\title{
Pure paclitaxel nanoparticles: preparation, characterization, and antitumor effect for human liver cancer SMMC-772I cells
}

This article was published in the following Dove Press journal: International Journal of Nanomedicine

\section{Chao $\mathrm{Wu}^{\prime}$ \\ $\mathrm{Yu} \mathrm{Gao}{ }^{2}$ \\ Ying Liu' \\ XiaoYan $\mathrm{Xu}{ }^{\prime}$}

'Pharmacy School, Jinzhou Medical University, Jinzhou, People's Republic of China; ${ }^{2}$ Department of Medical Oncology, First Affiliated Hospital of Jinzhou Medical University, Jinzhou, People's Republic of China

\section{Correspondence: Yu Gao}

Department of Medical Oncology, First Affiliated Hospital of Jinzhou Medical University, 5-2 Renmin Street, Guta, Jinzhou, Liaoning I2I00I, People's Republic of China

Tel +864I64673439

Email gaoyu_II16@I63.com
Introduction: Pure paclitaxel nanoparticles (PPN), consisting entirely of drug molecules, were prepared by the electrostatic spraying method as promising candidates for antitumor application. Compared with the traditional preparation method, the advantage of the electrostatic spraying method included high production rates, relatively small particle sizes, and ease of preparation. Materials and methods: Paclitaxel was used to prepared PPN by electrostatic spray. The electrostatic spray device included a constant speed pump with a syringe, a high-voltage power supply, and a metal foil receiver was used to prepare and evaluate PPN. The syringe drew off a certain amount of paclitaxel chloroform solution $(150 \mu \mathrm{g} / \mathrm{mL})$ and was placed on the constant speed injection pump. The dissolution behavior of PPN was evaluated by dissolution test and the presence of paclitaxel in PPN was detected by X-Ray powder diffraction and differential scanning calorimetry. Effect of PPN on SMMC-7721 cells were studied by cell uptake, cell apoptosis and antitumor study.

Results: The results of X-ray powder diffraction and differential scanning calorimetry characterization showed that the PPN were in an amorphous state. A dissolution study indicated that PPN have a significantly enhanced dissolution rate of paclitaxel. Moreover, SMMC-7721 tumor cells treated with PPN exhibited a distinctly high uptake rate that promoted cell apoptosis. An in vivo antitumor study demonstrated that PPN had significant antitumor efficacy.

Conclusion: All conclusions verified that electrostatic spraying is a potential technology for developing PPN, and PPN can be regarded as a promising treatment for cancer.

Keywords: electrostatic spraying, paclitaxel, SMMC-7721 cells, poorly water soluble drug, dissolution

\section{Introduction}

Paclitaxel is a broad-spectrum anticancer drug that is clinically effective against lung, liver, ovarian, breast, and other cancers. However, its solubility is less than $0.1 \mu \mathrm{g} / \mathrm{mL}$ in water, which seriously affects its bioavailability. ${ }^{1}$ Paclitaxel injection uses castor oil as the solvent for enhancing its solubility. Castor oil can induce hypersensitivity, and toxicity is inevitable. ${ }^{2,3}$ Paclitaxel for injection (albumin bound) has a low drug load (10\%), although it has low toxicity and good tolerance. Thus, improving its water solubility and bioavailability with effective preparation technology is a worthy scientific endeavor.

At present, research about paclitaxel dosage forms include liposomes, ${ }^{4,5}$ polymeric micelles or nanoparticles, ${ }^{6,7}$ nanocrystallines, ${ }^{8-11}$ mesoporous materials inclusion, ${ }^{12-14}$ and so on. The use of paclitaxel nanoparticles as a potential dosage form has attracted the attention of researchers. The solubilization principle shows that the particle size of an insoluble crystalline drug should be in the nanometer scale. Nanoparticles are made using anti-solvent methods, high-pressure homogenization, micronization 
technology, and so on, which increases the specific surface area and, thereby, the solubility and dissolution rate of insoluble drugs according to the Ostwald-Freundlich and Noyes-Whitney equation. Increasing the specific surface area of drug particles improves the contact between drug particles and biomembranes, and promotes the absorption of insoluble drugs. There are three technological methods for the preparation of paclitaxel nanocrystals: the first is the top-down type, which includes the medium grinding method, the homogenization method, and the microjet method; ${ }^{15}$ the second is the bottom-up type, which includes the precipitation method and the supercritical fluid method; ${ }^{16}$ the third is a combination of the first two techniques. ${ }^{17}$ These preparation technologies still present some challenges, including the complexity of the processes, their small scale, the poor reproducibility, and the high cost.

Electrostatic spray technology was studied in the early twentieth century. The principle is that as the surface charge density of droplets under a high-voltage electric field is increased, the surface is stretched and deformed, the droplets form a Taylor cone, and then the electric field makes the liquid flow along the Taylor cone and gradually produced a filament. This filament - under the multiple actions of the electric field force, surface tension, Kulun repulsive forces, and gravity - breaks into small droplets that, as a result of the repeated fragmentation process, gradually produce a series of smaller droplets, and these droplets in the space charge effect are forced to produce a spray. ${ }^{18-20}$ With the extension of time and distance, these droplets will become smaller and smaller. The electrostatic spray device comprises a constant speed pump with a syringe, a high-voltage power supply, and a metal foil receiver. It is applied to electrospray ionization mass spectrometry, pesticide spraying, and pharmaceutics. In pharmaceutics, the application of the technology is mainly focused on the preparation of polymer nanoparticles (such as poly(lactic-co-glycolic), lactose, ethyl cellulose, polyvinylpyrrolidone, etc.). ${ }^{21-24}$

Recently, we used the electrostatic spray method to prepare pure paclitaxel nanoparticles (PPN). Compared with the current nanocrystal preparation technology, the use of electrostatic spray technology for the preparation of pure insoluble drug nanoparticles has not been reported. The advantages of the method lie in the following: 1) a single-step process can produce pure drug nanoparticles with controllable and uniform particle size; 2) the equipment is simple and easy to be industrialized; and 3) pure drug nanoparticles are present in an amorphous state. In addition, the antitumor effect of PPN was evaluated by in vitro cell experiments and tumor inhibition experiments in vivo.

\section{Materials and methods Materials}

Paclitaxel bulk drug (PBD) was provided by the Tianfeng Biotechnology Company with a purity $>99 \%$. Tween 80 , methanol, acetonitrile, and trichloromethane were purchased from Tianjin Yongsheng Fine Chemical Co., Ltd. (Tianjin, People's Republic of China). SMMC-7721 cell lines, Tris-buffered saline Tween solution (TBST), PBS, RPMI 1640 medium, Annexin V-fluorescein isothiocyanate (FITC), MTT, propidium iodide (PI), fetal bovine serum (FBS), and trypsin were purchased from Shenyang Dingguo Biotechnology Co., Ltd. Paclitaxel injections (PIJ) were purchased from Beijing Union Pharmaceutical Factory.

\section{Preparation and evaluation of PPN}

The electrostatic spray device included a constant speed pump with a syringe, a high-voltage power supply, and a metal foil receiver. ${ }^{25,26}$ The syringe drew off a certain amount of paclitaxel chloroform solution $(150 \mu \mathrm{g} / \mathrm{mL})$ and was placed on the constant speed injection pump. The needle type (inner diameter) was $0.16 \mathrm{~mm}$, the voltage was $40 \mathrm{kV}$, the receiving distance was $20 \mathrm{~cm}$, and the injection rates were 50,100 , and $200 \mu \mathrm{L} / \mathrm{h}$. The $\mathrm{AC}$ power was on, and aluminum foil received PPN. The PPN obtained were defined as PPN50, PPN100, and PPN200, respectively.

The content of paclitaxel in PPN were determined by high-performance liquid chromatography (HPLC; L-2400, Hitachi, Japan) equipped with a UV spectroscope (UV-2000, Unico, USA) at $227 \mathrm{~nm}$. A Welch C18 column $(4.6 \times 250 \mathrm{~mm}, 5 \mu \mathrm{m})$ was used, the mobile phase was acetonitrile and water with a volume ratio of 50:50, and the flow rate was $1 \mathrm{~mL} / \mathrm{min}$. The content (C) of paclitaxel in PPN was calculated by the equation: $\mathrm{C}=\mathrm{M} 1 / \mathrm{M} 2$ ( $\mathrm{M} 1$ is the quality of paclitaxel in PPN, M2 is the quality of PPN).

\section{Characterization of PPN}

The particle size analysis of PPN was measured by laser diffraction using a Nano-ZS90 instrument from Malvern. The volume-weighted particle size distribution ranged from $0.040 \mu \mathrm{m}$ to $2,000 \mu \mathrm{m}$. The dispersing liquid of the suspensions was $0.02 \%$ Tween- 80 aqueous solution. The morphology of PPN was characterized by scanning electron microscopy (SEM; JSM-7001F, JEOL, Japan) and transmission electron microscopy (TEM; Tecnai G2F30, FEI, USA). The crystal transition or melting point of PPN was monitored by a differential scanning calorimetry (DSC; DSC-60, Shimadzu, Japan). The heating rate was $10^{\circ} \mathrm{C} /$ min under nitrogen. X-ray powder diffraction (XRD; Rigaku Ultima IV, Rigaku, Japan) was carried out to validate the solid state of paclitaxel. The step size was $0.02^{\circ}$ and the scanning rate was $4 \% \mathrm{~min}$ in a range $(2 \theta)$ from $3^{\circ} \mathrm{C}$ to $60^{\circ} \mathrm{C}$. 


\section{In vitro dissolution}

A dissolution instrument (RC806D, Tianda Tianfa, People's Republic of China) was used to conduct the dissolution test. PBD (30 mg) and PPN, including PPN50, PPN100, and PPN200 (30 mg), were suspended, respectively, in $900 \mathrm{~mL}$ PBS (pH 7.4) containing $1 \%$ Tween- 80 . The temperature of the medium was $37^{\circ} \mathrm{C} \pm 0.5^{\circ} \mathrm{C}$, and the paddle speed was $100 \pm 1 \mathrm{rpm}$. At predetermined intervals, samples $(5 \mathrm{~mL})$ were withdrawn from the dissolution medium to be analyzed by HPLC after being filtered through a $0.22-\mu \mathrm{m}$ microporous filtering film, and an equal volume of fresh medium was added. Experiments were conducted in triplicate.

\section{In vitro cytotoxicity}

PPN cytotoxicity assays were carried out in a liver cancer cell line (SMMC-7721). SMMC-7721 cells, at $10^{5}$ cells/well, were seeded in 96-well plates and cultured in a $\mathrm{CO}_{2}$ atmosphere at $37^{\circ} \mathrm{C}$ for $24 \mathrm{~h}$. RPMI 1640 medium with $10 \%$ FBS was removed and replaced with equal amounts of PBD suspension, PIJ, and PPN50 suspension. The medium of the suspension was RPMI 1640 medium containing 10\% FBS and 2\% hypromellose. The treated cells were incubated for 24,48 , and $72 \mathrm{~h}$. Each well was added $20 \mu \mathrm{L}$ MTT solution $(5 \mathrm{mg} / \mathrm{mL})$, and then the plate was incubated for $4 \mathrm{~h}$. After discarding the medium, $200 \mu \mathrm{L}$ DMSO was added to each well, and the plate was shaken for $10 \mathrm{~min}$. The absorbance was obtained using a microplate reader at a wavelength of $492 \mathrm{~nm}$.

\section{Flow cytometry assays}

Cell apoptosis was recorded by flow cytometry (Becton Dickinson, Zürich, Switzerland). SMMC-7721 cells $\left(1 \times 10^{5}\right.$ cells/well $)$ were seeded in six-well plates and cultured in a $\mathrm{CO}_{2}$ atmosphere at $37^{\circ} \mathrm{C}$ for $48 \mathrm{~h}$. PBD suspensions, PIJ, and PPN50 suspensions (corresponding to $10 \mathrm{ng} / \mathrm{mL}$ paclitaxel concentration) were added to the six-well plates and incubated for $48 \mathrm{~h}$. The medium was discarded, and trypsin was added for digesting the cells. Then, $500 \mu \mathrm{L}$ binding buffer dispersed the collected cells after centrifugation. Annexin V-FITC $(5 \mu \mathrm{L})$ and PI $(5 \mu \mathrm{L})$ were sequentially added to the system and, after $20 \mathrm{~min}$ of incubation, the apoptosis rate of the SMMC-7721 cells was determined in regard to time.

\section{Western blotting assay}

After the PBD suspension, PIJ, and PPN50 suspension treatments of the SMMC-7721 cells, the ultrasonic grinding method was used to extract the total protein from the SMMC-7721 cells. The total protein concentration was adjusted and determined using the bicinchoninic acid (BCA) method. The protein samples and the buffer solution with a volume ratio of $4: 1$ were mixed and boiled for $5 \mathrm{~min}$. A $10-\mu \mathrm{L}$ sample of each solution and the standard protein were analyzed by SDS-PAGE electrophoresis. TBST containing 5\% skim milk blocked the polyvinylidene fluoride (PVDF) membrane containing the separated proteins. The PVDF membrane was incubated with the primary antibodies (Bax, Bcl-2, and Caspase-3) overnight; thereafter, secondary antibodies were incubated with the membranes for 2 h. After enhanced chemiluminescence reagents (ECL) staining, the protein expression levels were investigated by a UVP gel analysis system (UVP, LLC., Upland, CA, USA).

\section{Cellular uptake study}

The counted SMMC-7721 cells were seeded in culture bottles and cultured in a $\mathrm{CO}_{2}$ atmosphere at $37^{\circ} \mathrm{C}$ for $24 \mathrm{~h}$. PPN50 suspensions (corresponding to 50,100 , and $150 \mu \mathrm{g} / \mathrm{mL}$ of paclitaxel concentrations) were added to the culture bottles and incubated for $0.5 \mathrm{~h}$. The PBD suspension was used as a comparator. In addition, a PPN50 suspension (corresponding to $50 \mu \mathrm{g} / \mathrm{mL}$ paclitaxel concentration) was added to the culture bottles and incubated for $0.5,1$, and $1.5 \mathrm{~h}$. The medium was discarded and the cells washed with PBS to remove free drugs. The cells were collected and broken by an ultrasonicator. The drug was extracted from the cell lysis solution. The extraction solvent was methyl tert-butyl ether. The organic layer was evaporated by a high-speed centrifuge (Hualida LNG-T120, People's Republic of China). The dried samples were dissolved in $50 \mu \mathrm{L}$ of the mobile phase again and vortexed for $5 \mathrm{~min}$. After centrifugation, $20 \mu \mathrm{L}$ of the supernatant was analyzed by HPLC with a UV-vis detector (HITACHI L-2400, Japan) at $227 \mathrm{~nm}$. The mobile phase was acetonitrile and water $(50: 50, \mathrm{~V} / \mathrm{V})$, and the flow rate was $1 \mathrm{~mL} / \mathrm{min}$.

\section{In vivo antitumor efficacy}

In vivo antitumor efficacy was evaluated using solid SMMC7721 cell tumor-bearing nude mice (Beijing Weitong Lihua Experimental Animal Technology Co. Ltd.). The animal experimental study conformed to the guidelines of the Jin Zhou Medical University Laboratory Animal Ethics Committee (no 11400700217882) and the committee approved the experiment. The right front legs of nude mice were implanted by with $5 \times 10^{4}$ SMMC-7721 cells dispersed in $0.1 \mathrm{~mL}$ of physiological saline through hypodermic injection. When the tumor volume reached $50-70 \mathrm{~mm}^{3}$, the tumor-bearing mice were randomly divided into four groups. Physiological saline, PBD, PIJ, and PPN50 suspension, at a dose of $20 \mathrm{mg} / \mathrm{kg}$, were administered via intraperitoneal injection at 3-day intervals. The length and width of each tumor was measured by a caliper before each administration. The tumor volume was calculated using the equation: $\mathrm{V}=0.5 \times$ length $\times$ 
(width) ${ }^{2}$. After dosing five times, the solid tumors were excised from the animals and fixed with paraformaldehyde for further study. Tumor sections were obtained by paraffin embedding and slicing, and were stained by H\&E. Then, fluorescence microscopy (Leica DMI 4000B, Germany) was used to observe cell apoptosis in the tumors.

\section{Statistical analysis}

Results are shown as the mean $\pm \mathrm{SD}$, and all data after statistical analysis testing (analysis of variance) were considered statistically significant.

\section{Results and discussion Preparation and morphological characterization of PPN}

The PPN were prepared in a single-step process using an electrostatic spraying method. The process is shown in Scheme 1. The droplets generated under high voltage formed a Taylor cone and produced a filament. Due to the combined action of the electric field force, surface tension, and gravity in the solvent evaporation process, the filaments turned into a string of beads; then, PPN were obtained by redispersion. Parameters such as drug concentration, injection velocity, spinning voltage, needle-collector distance, and needle diameter affected the particle sizes of PPN. The drug concentration and injection velocity were two key factors. A paclitaxel concentration of $150 \mathrm{mg} / \mathrm{mL}$ could produce uniform particles, but the high paclitaxel concentration caused needle clogging. SEM and TEM images in Figure $1 \mathrm{~A}-\mathrm{C}$ indicated that PPN with good dispersibility have a particle size of $90 \mathrm{~nm}$. Particle size determination results (Figure 1D) of PPN were in agreement with the images of SEM and TEM. When other parameters were constant, the particle size of PPN significantly increased with injection velocity $(50,100$, and $200 \mu \mathrm{L} / \mathrm{h})$. As shown in Figure 2A-C, SEM images displayed that the particle sizes of PPN (50, 100, and 200) were $90 \mathrm{~nm}, 200 \mathrm{~nm}$, and $3 \mu \mathrm{m}$. Moreover, the smaller the needle diameter, the smaller the PPN particle size. The content of paclitaxel in PPN reached $100 \%$, compared with $10 \%$ of the marketed Abraxane ${ }^{\circledR}$ preparation. $^{27}$

\section{$\mathrm{XRD}$ and DSC analysis}

XRD was undertaken to check the crystalline nature of paclitaxel in the PPN. The diffractograms of PBD and PPN are shown in Figure 3A. The pattern indicated that, compared with the crystal characteristic diffraction peaks of PBD at $5.6^{\circ}, 8.4^{\circ}$, and $12.5^{\circ}$, there were no crystal characteristic diffractions in PPN50, PPN100, and PPN200. This showed that paclitaxel in the PPN was presented in the amorphous state after the electrostatic spray. This may have been caused by the rapid volatilization of the solvent during the movement of the droplets in the electric field. Paclitaxel molecules do not form ordered crystals. DSC thermograms of PBD and PPN are shown in Figure 3B. PBD, as a crystal, presented a single endothermic peak at $223^{\circ} \mathrm{C}$. By comparison, PPN $(50,100$, and 200$)$ show an endothermic peak from $35^{\circ} \mathrm{C}$ to $85^{\circ} \mathrm{C}$, which showed PPN had a low glass-phase transition temperature. ${ }^{28}$ Paclitaxel began to melt and decompose, and became exothermic at $\sim 150^{\circ} \mathrm{C}$. These data indicated paclitaxel in the PPN existed in an amorphous state, which was identical to the XRD conclusion.

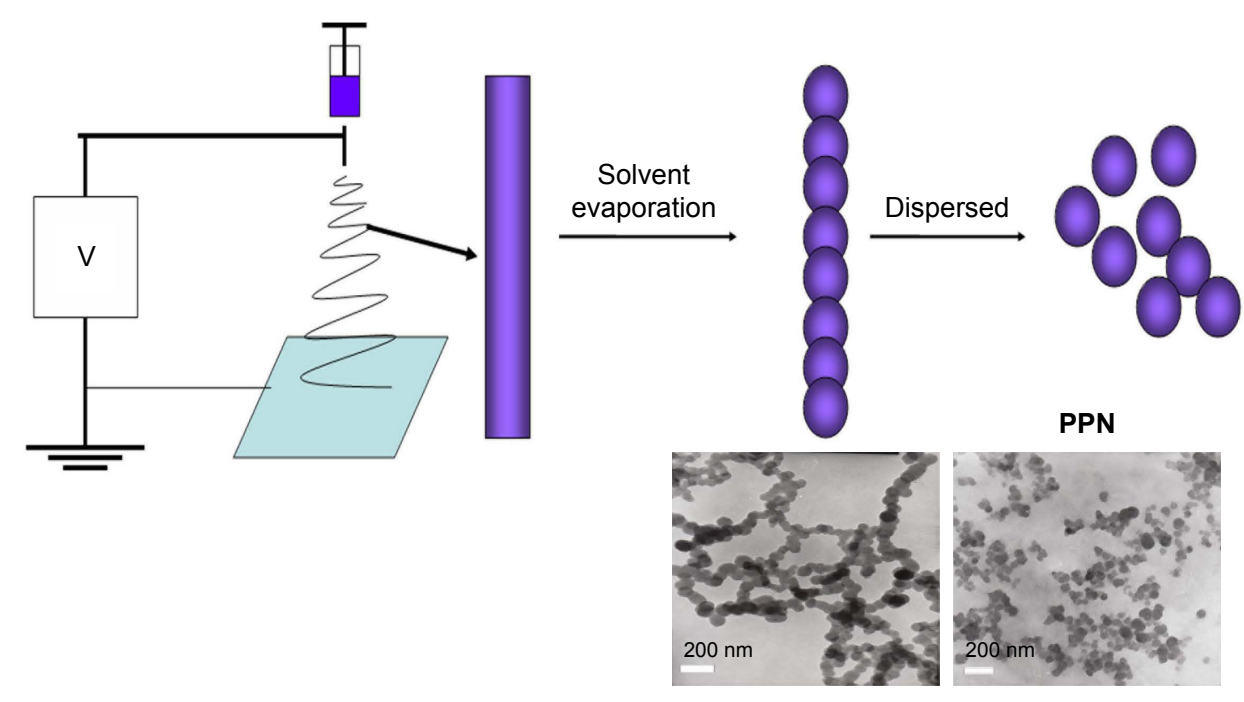

Scheme I Flow chart of pure paclitaxel nanoparticles (PPN) preparation process. 

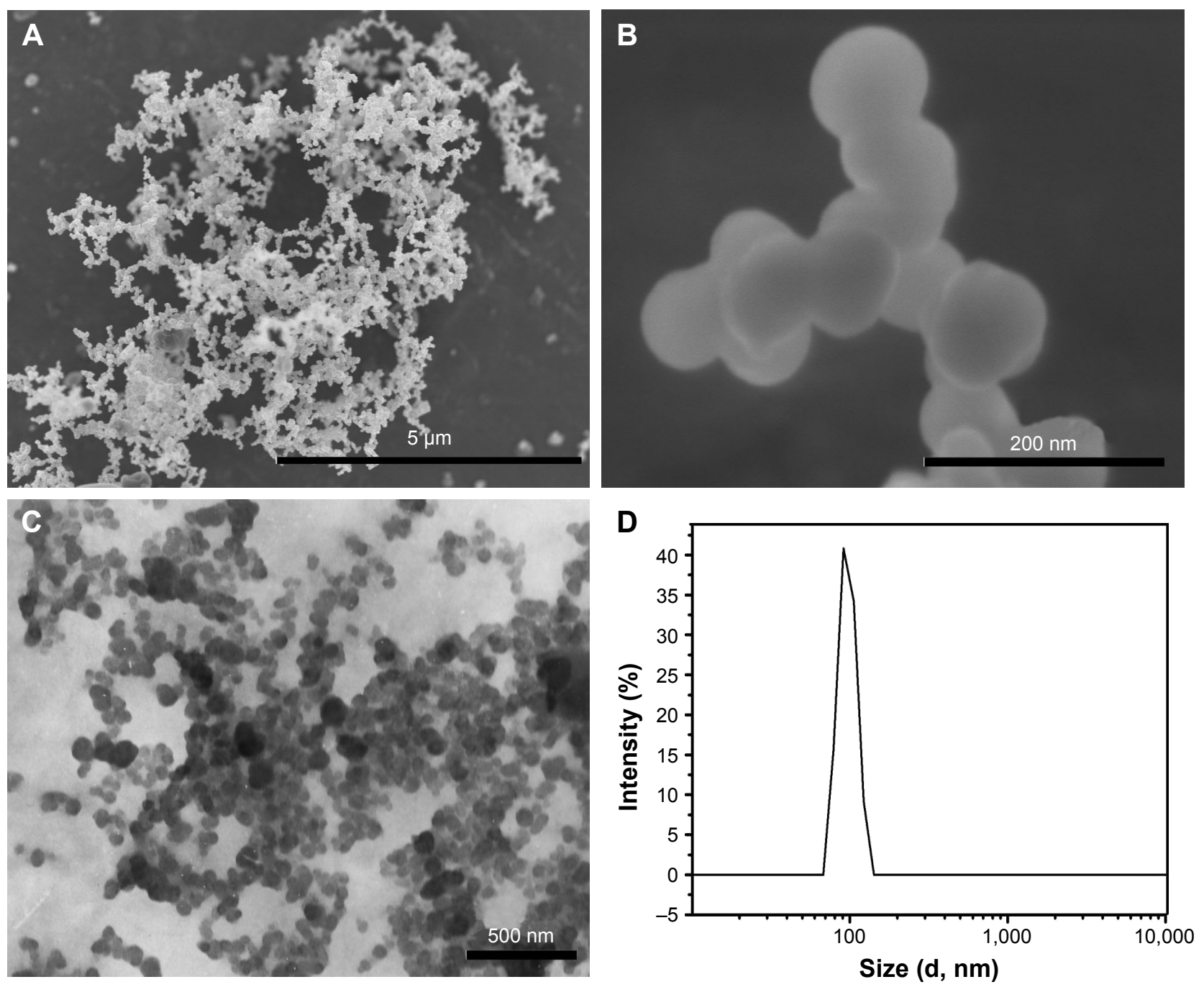

Figure I Scanning electron microscopy images of pure paclitaxel nanoparticles (PPN) (A and B), transmission electron microscopy (C) images of PPN, and particle size distribution of PPN50 (D).

\section{In vitro dissolution}

The dissolution profile of PBD and PPN is shown in Figure 4. The dissolution amount of PPN $(50,100$, and 200) at 5 min was above $80 \%$, whereas PBD could dissolve only to $13.1 \% \pm 1.24 \%$.
At $1 \mathrm{~h}$, the dissolution amount of PPN (50, 100, and 200) reached $\sim 100 \%$, whereas that of PBD had only risen to $38 \% \pm 3.53 \%$. The results indicated that the dissolution rate of PPN was significantly improved and showed a fast-release
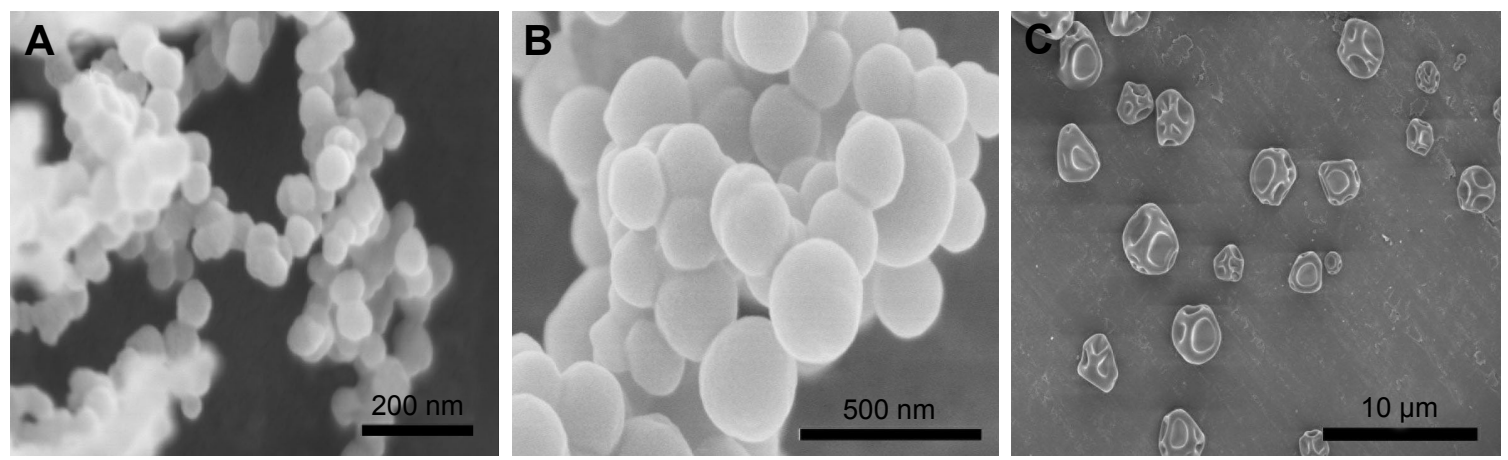

Figure 2 Scanning electron microscopy images of PPN50 (A), PPNI00 (B), and PPN200 (C). Abbreviation: PPN, pure paclitaxel nanoparticles. 

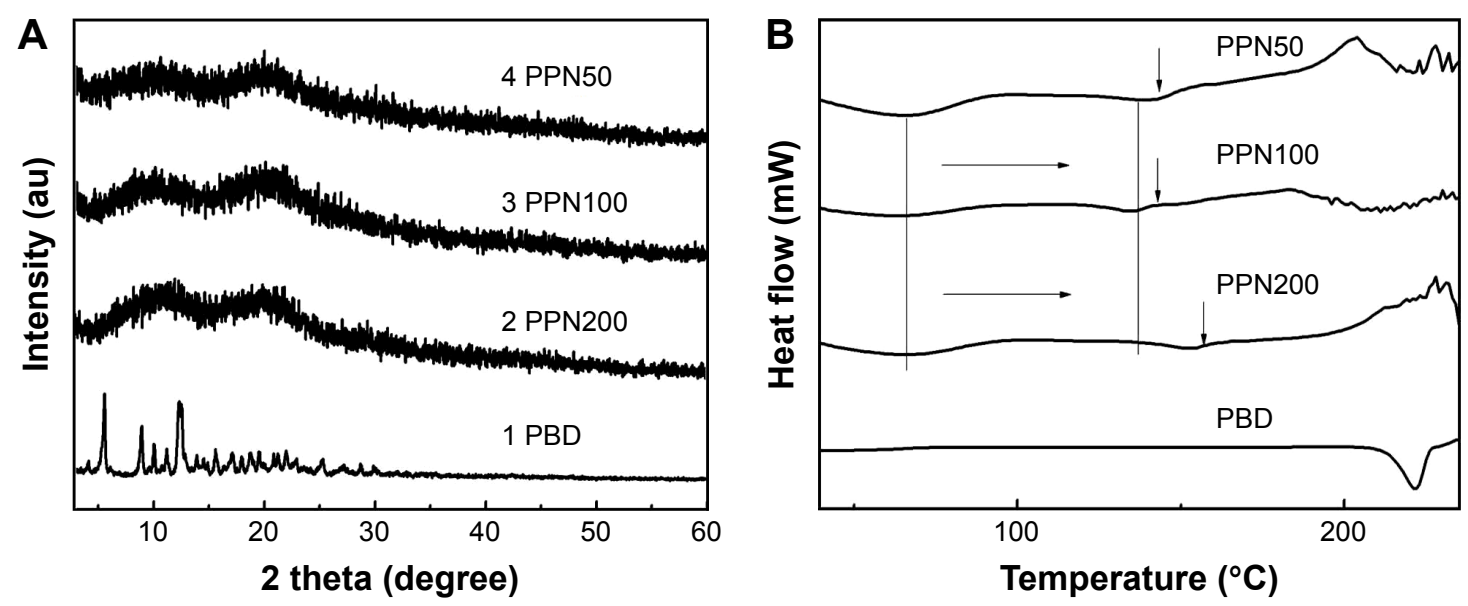

Figure 3 XRD (A) and DSC (B) patterns of PBD and PPN.

Abbreviations: XRD, X-ray powder diffraction; DSC, differential scanning calorimetry; PBD, paclitaxel bulk drug; PPN, pure paclitaxel nanoparticles.

effect. PPN50 had the best dissolving effect and the reason for the increase in the dissolution rate could be explained using the Noyes-Whitney equation. ${ }^{29}$ The increase in surface area due to the reduction in particle size led to the enhancement of the dissolution rate. Reduction of particle size decreased the diffusion distance, which was also a reason for the significantly increased dissolution rate. However, the most important factor was the amorphous state of the paclitaxel.

\section{In vitro cytotoxicity and apoptosis analysis}

In view of PPN50's good dissolution effect and smaller particle size, in vitro inhibition efficacy studies on the liver cancer cell line SMMC-7721 were carried out to assure that paclitaxel retained its activity after being processing through the electrostatic spray. To test cell viability in SMMC-7721 cells treated with PBD suspensions, PIJ and PPN50 suspensions, at different concentrations

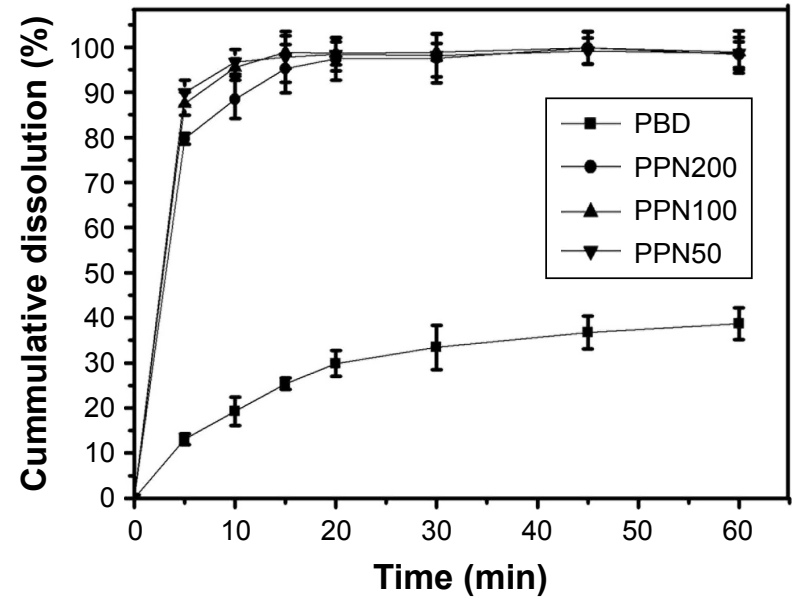

Figure 4 In vitro dissolution patterns of PBD and PPN ( $n=3)$. Abbreviations: PBD, paclitaxel bulk drug; PPN, pure paclitaxel nanoparticles. ranging from $1 \mathrm{ng} / \mathrm{mL}$ to $1,000 \mathrm{ng} / \mathrm{mL}$, were determined by an MTT assay. ${ }^{1}$ As shown in Figure $5 \mathrm{~A}-\mathrm{C}$, after $24 \mathrm{~h}$ of incubation, the PBD suspension $(1,000 \mathrm{ng} / \mathrm{mL})$ caused up to $28.6 \% \pm 4.29 \%$ cell death, whereas the cell death rate of the PPN50 suspension was $44.5 \% \pm 1.26 \%$. This was close to that of PIJ $(41.4 \% \pm 0.78 \%)$. When the concentration of the PPN50 suspension was less than $10 \mathrm{ng} / \mathrm{mL}$, the inhibitory effect was similar to that of the PBD suspension, but the inhibition rate increased significantly when the concentration was increased. At $48 \mathrm{~h}$ and $72 \mathrm{~h}$, the inhibitory effect of PPN50 (72.2\% $18.65 \%$ and $82.4 \% \pm 3.53 \%)$ at $1,000 \mathrm{ng} / \mathrm{mL}$ concentration was obviously better than that of the PBD suspension $(55.1 \% \pm 1.79 \%$ and $58.5 \% \pm 3.86 \%)$ and PIJ (56.8\% $\pm 1.20 \%$ and $68.4 \% \pm 5.19 \%$ ); moreover, the inhibition rate was closely related to drug concentration. The $\mathrm{IC}_{50}$ value after $24 \mathrm{~h}$ on SMMC-7721 of PBD suspension was found to be $48.9 \pm 4.68 \mu \mathrm{g} / \mathrm{mL}$, whereas those of the PPN50 suspension and PIJ were 0.521 \pm 0.072 and $3.09 \pm 0.491 \mu \mathrm{g} / \mathrm{mL}$, respectively. The $\mathrm{IC}_{50}$ value of the PBD suspension, the PPN50 suspension, and PIJ at $48 \mathrm{~h}$ were $622.24 \pm 27.9,68.49 \pm 5.64$, and $211 \pm 23.2 \mathrm{ng} / \mathrm{mL}$, respectively. At $72 \mathrm{~h}$, the $\mathrm{IC}_{50}$ value of PPN50 reached $10.03 \pm 1.04 \mathrm{ng} / \mathrm{mL}$, compared with $189.65 \pm 17.5 \mathrm{ng} / \mathrm{mL}$ for the PBD suspension and $40.1 \pm 1.62 \mathrm{ng} / \mathrm{mL}$ for PIJ. This demonstrated that PPN could significantly inhibit cell proliferation, which is attributed to PPN maintaining a high drug concentration in cells due to the direct cell uptake of PPN at the nanoscale as well as its increased drug dissolution. ${ }^{30}$ Apoptosis is a programmed process of self-destruction under certain physiological or pathological environments. It was measured by flow cytometry. ${ }^{31}$ As shown in Figure 6, PPN (10 ng/mL) induced $46.4 \% \pm 5.94 \%$ of SMMC-7721 cell apoptosis compared with $10.5 \% \pm 3.46 \%$ of PBD and, correspondingly, the apoptosis 

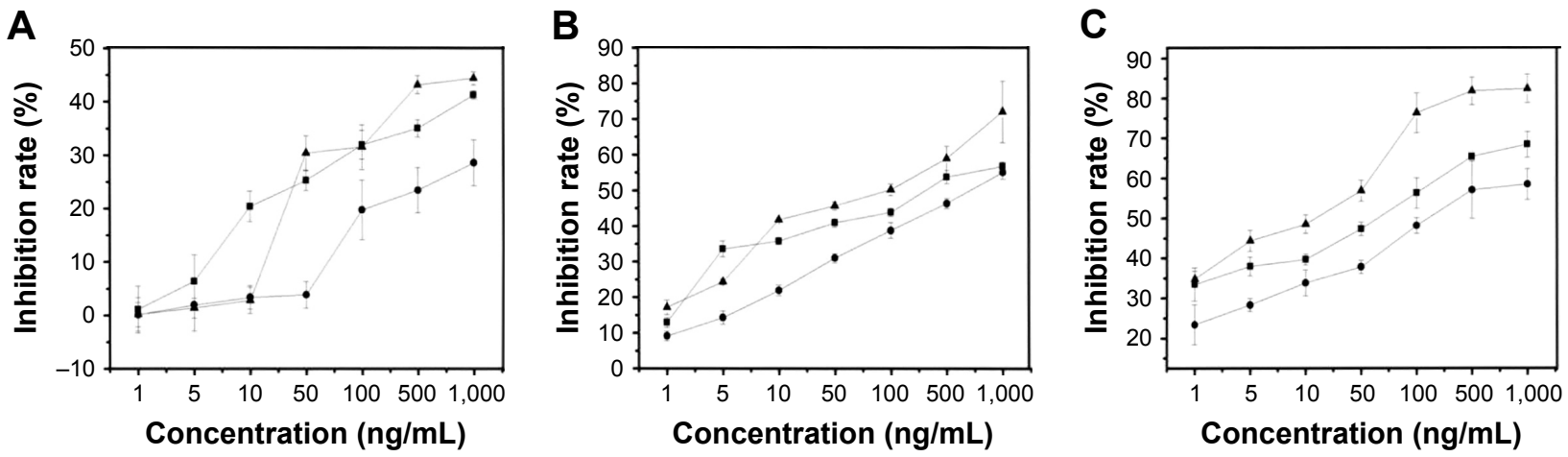

Figure 5 The cell cytotoxicity of PBD, PIJ, and PPN50 at $24 \mathrm{~h}(\mathbf{A}), 48 \mathrm{~h}(\mathbf{B})$, and $72 \mathrm{~h}(\mathbf{C})$ for SMMC-772I cells $(\mathrm{n}=3)$. Abbreviations: PBD, paclitaxel bulk drug; PIJ, paclitaxel injections; PPN, pure paclitaxel nanoparticles.

rate of PIJ was $38.1 \% \pm 4.27 \%$. This indicated that PPN had an excellent apoptosis-promoting effect on SMMC-7721 cells. The expression levels of the proapoptotic protein Bax, the anti-apoptotic protein Bcl-2, and Caspase-3 further verified the conclusions of the flow cytometry studies. As shown in Figure 7, compared with the PBD group, in the PPN group the protein expression of Bax was induced prominently, and the protein expression level of Bcl-2 was suppressed, which led to an increase of the $\mathrm{Bax} / \mathrm{Bcl} 2$ ratio. The proapoptotic tendency dominated in the progress of cells. Moreover, Caspase-3, as one of the main apoptosis proteins, was distinctly enhanced. The relative gray values further proved the above results. These results make it clear that the intrinsic apoptotic pathway might be involved in PPN-induced apoptosis. It obviously means that PPN has good antitumor potential.

\section{Cellular uptake analysis}

PPN could be absorbed directly and accumulated at the tumor site by the enhanced permeability and retention effect. HPLC was conducted to measure if PPN could be effectively taken up by SMMC-7721 cells. ${ }^{32}$ Figure $8 \mathrm{~A}$ shows the concentration change of paclitaxel in SMMC-7721 cells treated with PPN at various time periods. At $0.5 \mathrm{~h}$, the concentration of paclitaxel was $2.59 \pm 0.786 \mu \mathrm{g} / \mathrm{mL}$, compared with $1.37 \pm 0.213 \mu \mathrm{g} / \mathrm{mL}$ of PBD. With increasing duration from $0.5 \mathrm{~h}$ to $1.5 \mathrm{~h}$, the concentration of paclitaxel in the PPN group increased from $2.59 \pm 0.786 \mu \mathrm{g} / \mathrm{mL}$ to $7.35 \pm 0.289 \mu \mathrm{g} / \mathrm{mL}$. By comparison, the concentration of paclitaxel in the PIJ group was only up to $6.37 \pm 0.516 \mu \mathrm{g} / \mathrm{mL}$ at $1.5 \mathrm{~h}$. The increase in the uptake amount indicated that the cellular uptake of PPN was time dependent and, over time, the intake of PPN was more than that of PIJ. Figure $8 \mathrm{~B}$ shows that the amount of PPN uptake also gradually increased and was close to that of PIJ at $0.5 \mathrm{~h}$ when the concentration of PPN increased from $50 \mu \mathrm{g} / \mathrm{mL}$ to $150 \mu \mathrm{g} / \mathrm{mL}$. The PBD group had the least amount of cell uptake. Thus, the uptake of PPN was also concentration dependent. These results show that PPN could be taken up directly and maintained at high drug concentrations in cells, which promotes cell death.

\section{Evaluation of therapeutic effect in solid tumor-bearing mice}

The greatly enhanced tumor cell apoptosis caused by PPN heightened our expectation of the eventual efficacy of PPN in
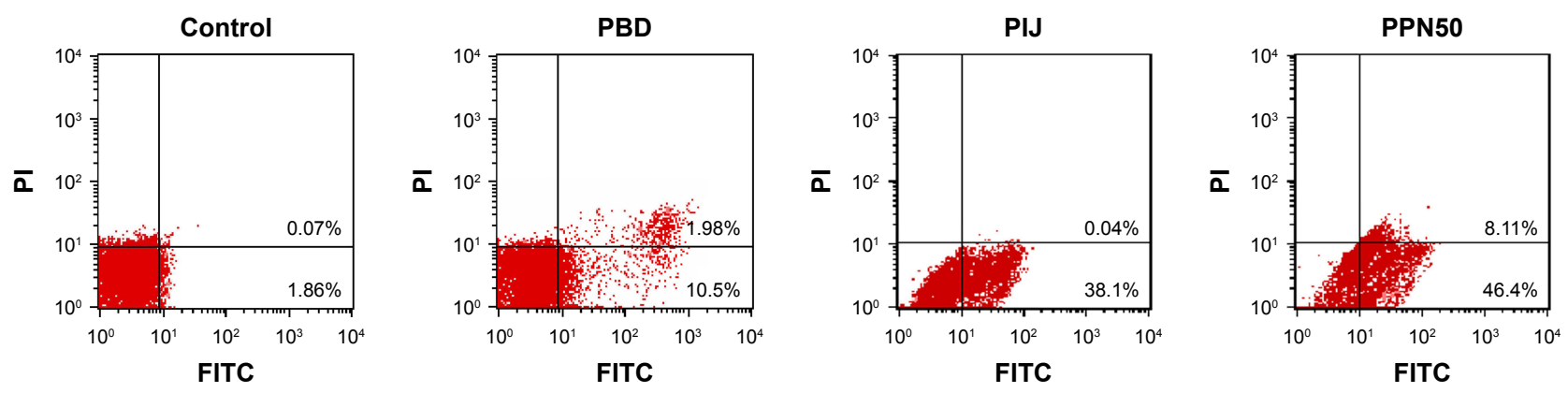

Figure 6 Cell apoptosis of PBD, PIJ, and PPN50 $(n=3)$.

Abbreviations: PBD, paclitaxel bulk drug; PIJ, paclitaxel injections; PPN, pure paclitaxel nanoparticles; FITC, fluorescein isothiocyanate; PI, propidium iodide. 


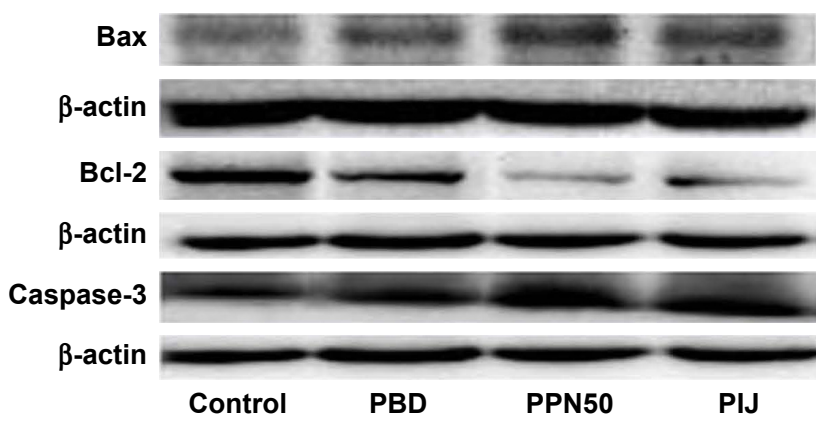

Figure $7 \mathrm{Bax}, \mathrm{Bcl}-2$, and caspase-3 protein expression levels of the PBD, PIJ, and PPN50.

Abbreviations: PBD, paclitaxel bulk drug; PIJ, paclitaxel injections; PPN, pure paclitaxel nanoparticles.

anticancer therapy. Therefore, a comparative evaluation of the antitumor performance of PBD, PIJ, and PPN was carried out on a tumor-bearing nude mouse model.$^{33}$ As shown in Figure 9A and $\mathrm{B}$, the tumor progression results indicate that both PPN suspensions yielded definite tumor inhibition in comparison with the control group. The treatment group with PPN was significantly better at inhibiting tumor volume compared with the PIJ group. Calculated tumor inhibition rates, based on the averaged volumes of tumors on the animals, were $22.9 \% \pm 1.07 \%$ and $61.7 \% \pm 5.36 \%$ for the PBD and PPN suspension treatment groups, respectively. The tumor inhibition rates between these two groups were significantly different from each other. Moreover, the PPN group obtained a slightly better effect than the PIJ group $(56.4 \% \pm 1.78 \%)$. The results can be attributed to the increased paclitaxel dissolution from PPN and accumulation of PPN with smaller particle sizes in the tumors, which led to a high drug concentration atmosphere and accelerated the death of cancer cells. Histopathological examination of the excised tumor tissues was undertaken, and the representative histological photomicrographs are shown in Figure 9C. As suggested by pathologists, the tumor tissue in the PPN group had larger necrotic areas compared with the PIJ group, and the nuclei showed more marked shrinkage and fragmentation. After H\&E staining, the purple in the sections represented the viable tumor cells. The saline group observed many viable tumor cells. The PPN and PIJ groups evidently presented less viable tumor cells, and the PPN group had a better anti-proliferation effect.

\section{Conclusion}

In summary, PPN obtained by an electrostatic spraying method in a simple manner had adjustable particle sizes. In vitro antitumor experiments showed that PPN could be ingested by cells in significant amounts and inhibit cell proliferation. Compared with PBD and PIJ, PPN had good antitumor effects in vivo. Overall, this study suggested that the electrostatic spraying method in preparing PPN in comparison with traditional nanocrystal preparation methods holds promise in application. These advantages such as single-step process, the simple equipment, amorphous state, and so on are beneficial to industrial production.

\section{Acknowledgments}

This study was supported by the National Natural Science Foundation of China (grant no 81302707), the Natural Science Foundation of Liaoning Province (grant no 20170540366), Liaoning province talent project support programs in colleges and universities (grant no LJQ2015065), and the Principal Fund-Aohong-boze-clinical medicine construction Special Fund (grant no XZJJ20140205).
A

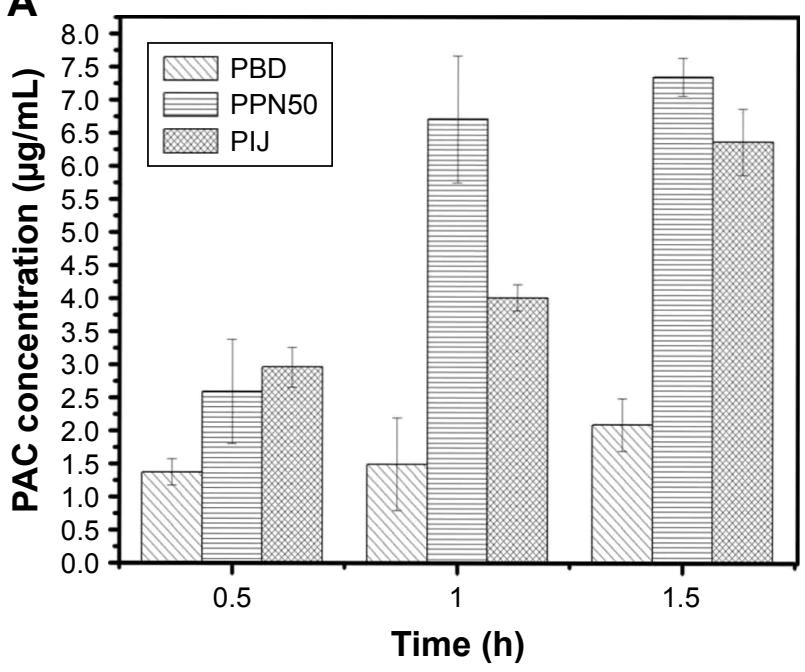

B

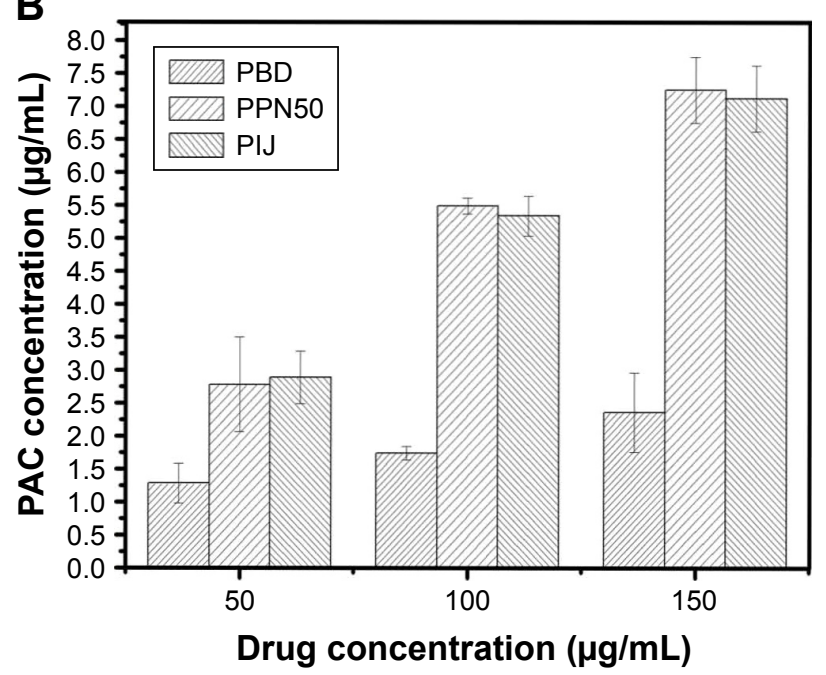

Figure 8 Cellular uptake of PBD, PIJ, and PPN50 $(n=3)$.

Notes: (A) time dependence; $(\mathbf{B})$ concentration dependence.

Abbreviations: PBD, paclitaxel bulk drug; PIJ, paclitaxel injections; PPN, pure paclitaxel nanoparticles; PAC, paclitaxel. 

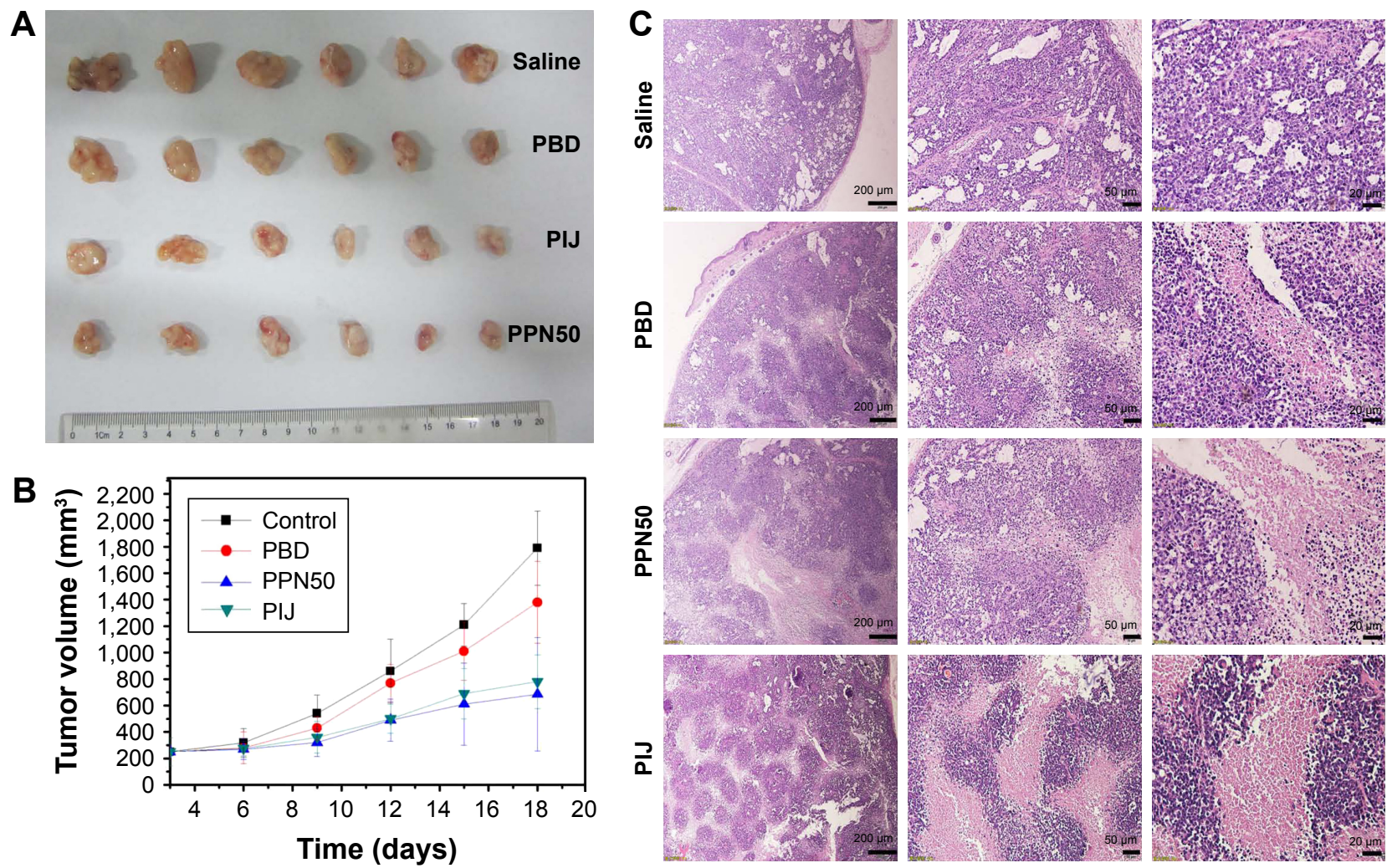

Figure 9 (A) The images of tumor tissues excised from the tumor-bearing nude mice of the saline, PBD, PIJ, and PPN50 groups. (B) The tumor volume curves of the saline, PBD, PIJ, and PPN50 groups. (C) Histological examination of excised tumor tissues of the saline, PBD, PIJ, and PPN50 groups under different magnifications. Abbreviations: PBD, paclitaxel bulk drug; PIJ, paclitaxel injections; PPN, pure paclitaxel nanoparticles.

\section{Disclosure}

The authors report no conflicts of interest in this work.

\section{References}

1. Sharma S, Verma A, Teja BV, Shukla P, Mishra PR. Development of stabilized paclitaxel nanocrystals: in-vitro and in-vivo efficacy studies. Eur J Pharm Sci. 2015;69:51-60.

2. Szebeni J. Complement activation-related pseudoallergy: a new class of drug-induced acute immune toxicity. Toxicology. 2005;216(2-3):106-121.

3. Szebeni J, Alving CR, Savay S, et al. Formation of complement-activating particles in aqueous solutions of Taxol: possible role in hypersensitivity reactions. Int Immunopharmacol. 2001;1(4):721-735.

4. Yamashita S, Katsumi H, Hibino N, et al. Development of PEGylated aspartic acid-modified liposome as a bone-targeting carrier for the delivery of paclitaxel and treatment of bone metastasis. Biomaterials. 2018;154:74-85.

5. Jiang X, Zhang B, Zhou Z, et al. Enhancement of radiotherapy efficacy by pleiotropic liposomes encapsulated paclitaxel and perfluorotributylamine. Drug Deliv. 2017;24(1):1419-1428.

6. Wu Q, Du F, Luo Y, et al. Poly(ethylene glycol) shell-sheddable nanomicelle prodrug of camptothecin with enhanced cellular uptake. Colloids Surf B Biointerfaces. 2013;105:294-302.

7. Wais U, Jackson AW, Zuo Y, Xiang Y, He T, Zhang H. Drug nanoparticles by emulsion-freeze-drying via the employment of branched block copolymer nanoparticles. J Control Release. 2016;222:141-150.

8. Zhou M, Zhang X, Yu C, Nan X, Chen X, Zhang X. Shape regulated anticancer activities and systematic toxicities of drug nanocrystals in vivo. Nanomedicine. 2016;12(1):181-189.

9. Dan J, Ma Y, Yue P, et al. Microcrystalline cellulose-carboxymethyl cellulose sodium as an effective dispersant for drug nanocrystals: a case study. Carbohydr Polym. 2016;136:499-506.
10. Sarnes A, Kovalainen M, Häkkinen MR, et al. Nanocrystal-based peroral itraconazole delivery: superior in vitro dissolution enhancement versus Sporanox ${ }^{\circledR}$ is not realized in vivo drug absorption. $J$ Control Release. 2014;180:109-116.

11. Sarnes A, Østergaard J, Jensen SS, et al. Dissolution study of nanocrystal powders of a poorly soluble drug by UV imaging and channel flow methods. Eur J Pharm Sci. 2013;50(3-4):511-519.

12. Zhao Z, Wu C, Zhao Y, Hao Y, Liu Y, Zhao W. Development of an oral push-pull osmotic pump of fenofibrate-loaded mesoporous silica nanoparticles. Int J Nanomedicine. 2015;10:1691-1701.

13. Zhang Z, Quan G, Wu Q, et al. Loading amorphous Asarone in mesoporous silica SBA-15 through supercritical carbon dioxide technology to enhance dissolution and bioavailability. Eur J Pharm Biopharm. 2015; 92:28-31.

14. Zhang C, Li C, Huang S, et al. Self-activated luminescent and mesoporous strontium hydroxyapatite nanorods for drug delivery. Biomaterials. 2010;31(12):3374-3383.

15. Srivalli KM, Mishra B. Preparation and pharmacodynamic assessment of ezetimibe nanocrystals: effect of P-gp inhibitory stabilizer on particle size and oral absorption. Colloids Surf B Biointerfaces. 2015; 135:756-764.

16. Du J, Li X, Zhao H, et al. Nanosuspensions of poorly water-soluble drugs prepared by bottom-up technologies. Int J Pharm. 2015; 495(2):738-749.

17. Sinha B, Müller RH, Möschwitzer JP. Systematic investigation of the cavi-precipitation process for the production of ibuprofen nanocrystals. Int J Pharm. 2013;458(2):315-323.

18. Zhao S, Castle GSP, Adamiak K. Factors affecting deposition in electrostatic pesticide spraying. J Electrostat. 2008;66:594-601.

19. Pascuzzi S, Cerruto E. Spray deposition in "tendone" vineyards when using a pneumatic electrostatic sprayer. Crop Prot. 2015;68: $1-11$. 
20. Colbert SA, Cairncross RA. A computer simulation for predicting electrostatic spray coating patterns. Powder Technol. 2005;151(1-3):77-86.

21. Wu Y, MacKay JA, McDaniel JR, Chilkoti A, Clark RL. Fabrication of elastin-like polypeptide nanoparticles for drug delivery by electrospraying. Biomacromolecules. 2009;10(1):19-24.

22. Sridhar R, Ramakrishna S. Electrosprayed nanoparticles for drug delivery and pharmaceutical applications. Biomatter. 2013;3(3):pii: e24281.

23. Zamani M, Prabhakaran MP, Ramakrishna S. Advances in drug delivery via electrospun and electrosprayed nanomaterials. Int J Nanomedicine. 2013;8:2997-3017.

24. Bohr A, Kristensen J, Dyas M, Edirisinghe M, Stride E. Release profile and characteristics of electrosprayed particles for oral delivery of a practically insoluble drug. J R Soc Interface. 2012;9(75):2437-2449.

25. Yang YY, Liu ZP, Yu DG, Wang K, Liu P, Chen X. Colon-specific pulsatile drug release provided by electrospun shellac nanocoating on hydrophilic amorphous composites. Int J Nanomedicine. 2018;13: 2395-2404

26. Liu Z, Wang H, Wang E, Zhang X, Yuan R, Zhu Y. Superhydrophobic poly(vinylidene fluoride) membranes with controllable structure and tunable wettability prepared by one-step electrospinning. Polymer. 2016;82:105-113.

27. Nyman DW, Campbell KJ, Hersh E, et al. Phase I and pharmacokinetics trial of ABI-007, a novel nanoparticle formulation of paclitaxel in patients with advanced nonhematologic malignancies. J Clin Oncol. 2005;23(31):7785-7793.
28. Wlodarski K, Zhang F, Liu T, Sawicki W, Kipping T. Synergistic effect of polyvinyl alcohol and copovidone in itraconazole amorphous solid dispersions. Pharm Res. 2018;35(1):16.

29. Wu C, Sun X, Zhao Z, et al. Synthesis of novel core-shell structured dual-mesoporous silica nanospheres and their application for enhancing the dissolution rate of poorly water-soluble drugs. Mater Sci Eng C Mater Biol Appl. 2014;44:262-267.

30. Zhang J, Li Y, An FF, Zhang X, Chen X, Lee CS. Preparation and size control of sub-100 nm pure nanodrugs. Nano Lett. 2015;15(1): 313-318.

31. Zhang L, Tian B, Li Y, et al. A copper-mediated disulfiram-loaded $\mathrm{pH}$-triggered PEG-shedding TAT peptide-modified lipid nanocapsules for use in tumor therapy. ACS Appl Mater Interfaces. 2015;7(45): 25147-25161.

32. Zhang Y, Wang J, Bai X, Jiang T, Zhang Q, Wang S. Mesoporous silica nanoparticles for increasing the oral bioavailability and permeation of poorly water soluble drugs. Mol Pharm. 2012;9(3):505-513.

33. Ni D, Ding H, Liu S, et al. Superior intratumoral penetration of paclitaxel nanodots strengthens tumor restriction and metastasis prevention. Small. 2015;11(21):2518-2526.
International Journal of Nanomedicine

\section{Publish your work in this journal}

The International Journal of Nanomedicine is an international, peerreviewed journal focusing on the application of nanotechnology in diagnostics, therapeutics, and drug delivery systems throughout the biomedical field. This journal is indexed on PubMed Central, MedLine, CAS, SciSearch $®$, Current Contents ${ }^{\circledR} /$ Clinical Medicine,

\section{Dovepress}

Journal Citation Reports/Science Edition, EMBase, Scopus and the Elsevier Bibliographic databases. The manuscript management system is completely online and includes a very quick and fair peer-review system, which is all easy to use. Visit http://www.dovepress.com/ testimonials.php to read real quotes from published authors. 